\title{
Computed tomography and pulmonary function abnormalities in sickle cell disease
}

\author{
K.P. Sylvester*, S.R. Desai ${ }^{\mp}$, A.U. Wells ${ }^{\S}$, D.M. Hansell ${ }^{\S}$, M. Awogbade ${ }^{+}$, \\ S.L. Thein ${ }^{\#,+}$ and A. Greenough*
}

ABSTRACT: The aim of this study was to determine whether patients with sickle cell disease (SCD) in steady state had pulmonary abnormalities seen on high-resolution computed tomography (HRCT) and whether any abnormalities correlated with contemporaneously diagnosed lung function abnormalities. A subsidiary question was whether the results of a noninvasive measure of haemolysis (end-tidal carbon monoxide (ETCO) levels) correlated with pulmonary function abnormalities.

Thirty three patients with SCD, median (range) age 36 yrs (17-67 yrs) were examined. The degree of lobar volume loss and ground-glass opacification and prominence of central vessels on HRCT were quantitatively assessed. Pulmonary function was assessed by measurements of lung volumes, spirometry, gas transfer and oxygen saturation. ETCO levels were measured using an end-tidal CO monitor.

Forced expiratory volume in one second (FEV 1 ), forced vital capacity and total lung capacity significantly correlated with HRCT findings, particularly lobar volume loss. ETCO levels significantly negatively correlated with $\mathrm{FEV}_{1}$, vital capacity measured using a plethysmograph, specific airway conductance and arterial oxygen saturation measured by pulse oxymetry.

In conclusion, the present results suggest that high-resolution computed tomography noninvasive assessment of haemolysis might be useful to identify sickle cell disease patients with respiratory function impairment.

KEYWORDS: Haemolysis, high-resolution computed tomography, pulmonary function, sickle cell disease

A dults with sickle cell disease (SCD) may develop sickle chronic lung disease (SCLD) [1]. When deoxygenated, sickle haemoglobin (HbS) undergoes conformational changes; crystallised $\mathrm{HbS}$ molecules form a viscous solution within erythrocytes, "stiffening" them and changing them from their normal biconcave shape to a sickle shape, which is less deformable and subject to haemolysis. The sickle cells occlude vessels causing vascular injury, especially to organs with sluggish circulation and in atelectatic areas of the lung. Cells that have sickled repeatedly become irreversibly sickled. Deoxygenation is maximal in the venous circulation and the sickle cells can cause extensive and progressive damage to the pulmonary vascular bed. Approximately $4 \%$ of SCD patients develop SCLD leading to end-stage respiratory failure, characterised by hypoxaemia, restrictive lung disease, cor pulmonale and chest radiograph evidence of diffuse lung abnormalties. Pulmonary function tests are used to document the severity of lung disease in SCD, but some patients cannot successfully undertake such examinations. Recently, high-resolution computed tomography (HRCT) has been shown to be of value in the evaluation of patients with diffuse lung diseases [2-4]. Whether HRCT assessment of the lungs of patients with SCD is useful, however, has rarely been explored. In one previous study [5], it was shown that $\sim 40 \%$ of patients had evidence of interstitial disease on HRCT, but no significant relationships between the pulmonary function test results and HRCT abnormalities were demonstrated. The time interval between HRCT and pulmonary function testing, however, was large, with a range from 1 month to 1 yr. Thus, the aim of this study was to characterise and quantify any steady-state abnormalities on HRCT in patients with SCD and to determine whether they correlated with contemporaneously diagnosed lung function abnormalities.

The lung damage seen in SCD appears to be a complication of chronic haemolysis and repeated episodes of pulmonary vaso-occlusion [1]. It seems likely then that assessment of the severity
AFFILIATIONS

*Division of Asthma, Allergy and Lung Biology,

"Division of Gene and Cell Based Therapy, King's College London School of Medicine at Guy's, King's College \& St Thomas' Hospitals, and 'Depts of Radiology and Interstitial Lung Unit,

'Haematological Medicine, King's College Hospital, and

${ }^{\S}$ Dept of Radiology, Royal Brompton Hospital, London, UK.

CORRESPONDENCE

A. Greenough

Dept of Child Health

4th Floor Golden Jubilee Wing

King's College Hospital

Denmark Hill

Bessemer Rd

London

SE5 9PJ

UK

Fax: 442073468284

E-mail: anne.greenough@kcl.ac.uk

Received:

January 172006

Accepted after revision:

May 102006

\section{SUPPORT STATEMENT}

This study was supported by a grant awarded to A. Greenough from the

Amanda Smith Charitable Trust

(London, UK) to support K.P.

Sylvester, and in part by a

Development Grant from the Medical Research Council (London, UK) to

S.L. Thein (G0001249), and a Pump Priming Grant to S.R. Desai awarded by the Royal College of Radiologists (London, UK).

European Respiratory Journal

Print ISSN 0903-1936

Online ISSN 1399-3003 
of haemolysis might help to identify SCD patients with pulmonary function abnormalities. Haemolysis can be assessed by analysing the carboxyhaemoglobin level of venous blood samples [6]. The haem, released as a result of premature destruction of erythrocytes in patients with SCD, is degraded by the haem oxygenase enzyme complex to equimolar amounts of carbon monoxide (CO) and biliverdin [7, 8]. The $\mathrm{CO}$ combines with haemoglobin to form carboxyhaemoglobin. Carboxyhaemoglobin levels can be measured using a chromatographic technique [9] and closed rebreathing system. Unfortunately, the technique is invasive and requires patient cooperation. An alternative method of assessing haemolysis is to measure exhaled breath CO levels [10]. The catabolism of haem from erythrocytes accounts for $\sim 70 \%$ of the body's CO production [10]. It has been previously demonstrated in children with SCD that exhaled CO levels, measured using a nonvolitional technique, correlated with invasively measured markers of haemolysis [11]. Thus, a subsidiary aim of this study was to determine whether end-tidal CO (ETCO) levels were correlated with conventional markers of haemolysis in older patients with SCD, and, if so, whether ETCO levels were related to lung function abnormalities.

\section{METHODS}

\section{Subjects}

A prospective study of patients with SCD attending a specialist clinic at the Dept of Haematological Medicine, King's College Hospital, London, UK, was performed. The patients were eligible for the study regardless of any previous history of pulmonary problems and consecutive patients who gave written informed consent were recruited. The study was approved by the King's College Hospital Research Ethics Committee. All but two of the patients underwent both lung function and HRCT assessments on the same day. In the two exceptional cases, the second assessment was made within 2 weeks of the first.

A detailed history was obtained from each patient and respiratory function tests undertaken. No testing was performed if the patient had a history of an upper respiratory tract infection (URTI) within the previous 2 weeks or of a vasoocclusive crisis within the previous month. Short-acting bronchodilators were withheld for $\geqslant 12 \mathrm{~h}$ before testing and smokers were asked to abstain from smoking for $\geqslant 24 \mathrm{~h}$ prior to testing.

\section{HRCT}

All HRCT examinations were carried out using a dual detector helical computed tomography (CT) scanner (HiSpeed NX/i; GE Medical Systems, Milwaukee, WI, USA). Scans were obtained in the supine and prone positions, at full inspiration, with $1.5-\mathrm{mm}$ collimation at $10-\mathrm{mm}$ intervals; images were reconstructed using a high spatial-frequency (bone) algorithm. All studies were stored and subsequently viewed at window settings appropriate for visualisation of the lung parenchyma (window centre -550 HU; window width $1500 \mathrm{HU}$ ). The extent and severity of CT patterns in individual lobes (with the lingula considered as a separate lobe) were independently quantified on supine images by two thoracic radiologists unaware of the lung function testing results. Discrepant observations were resolved by a consensus review. Prone images were reviewed to determine whether abnormalities in the dependent lung represented established disease (shown if the abnormalities persisted) or (normal) dependent atelectasis (shown if the abnormalities did not persist on the prone images).

The abnormalities were quantified as follows: 1 ) the severity of lobar volume loss $(0=$ none; $1=$ mild; $2=$ severe $) ; 2)$ the prominence of peripheral vessels (defined as those vessels within $2 \mathrm{~cm}$ of the pleural surface) and the prominence of central pulmonary vessels $(0=$ none; $1=$ mild; $2=$ moderate; $3=$ severe); and 3) the extent of thickened interlobular septa $(0=$ none; $1=$ less than five interlobular septa; $2=$ more than five interlobular septa or $\leqslant 50 \%$ involvement of the pleural surface; $3=>50 \%$ involvement of the pleural surface). The extent of the following patterns were scored on a continuous scale to the nearest 5\%: 1) a reticular pattern (defined as innumerable interlacing line shadows suggesting a mesh [12]); 2) groundglass opacification (defined as a hazy increased attenuation of lung, but with preservation of vascular and bronchovascular markings [12]); and 3) nodules. The presence or absence of tractional dilatation of segmental and subsegmental airways ("traction bronchiectasis") within regions of ground-glass opacification and irregular linear opacities (defined as any linear opacity of irregular thickness of 1-3 mm, distinct from interlobular septa, bronchovascular bundles and nodular opacities [12]) was recorded.

\section{Lung function measurements}

Forced expiratory volume in one second (FEV1), forced vital capacity (FVC) and peak expiratory flow were measured using a heated pneumotachograph (Masterscreen PFT; Viasys Healthcare, Warwick, UK) and FEV1/FVC was calculated and expressed as a percentage. A minimum of three flowvolume loop results within $5 \%$ of each other were recorded and the flow-volume loop with the highest FEV1 analysed. Lung volumes were assessed by measurement of total lung capacity (TLCpleth), functional residual capacity, vital capacity (VCpleth) and residual volume (RVpleth) using a constant volume whole-body plethysmograph (Morgan TLC; Morgan Medical, Rainham, UK). Measurements were performed at least twice and the mean of values within $5 \%$ of each other recorded. Prior to commencing measurement by plethysmography, the subject sat in the plethysmograph for a minimum of $2 \mathrm{~min}$ to allow the temperature and pressure within it to equilibrate. The subject was then instructed to breathe normally through the mouthpiece attached to the pneumotachograph. Measurements of mouth pressure and box pressure were made during a panting manoeuvre. The shutter remained closed for five panting breaths. The shutter was then released and the subject instructed to make a maximal expiratory manoeuvre to RV. Once RV was reached, the subject was instructed to inspire maximally to TLC. Total lung gas transfer for carbon monoxide $(D \mathrm{~L}, \mathrm{CO})$, gas transfer per unit lung volume of carbon monoxide $(\mathrm{KCO})$, alveolar volume and VCSB were assessed using the single-breath gas transfer technique (Masterscreen PFT; Viasys Healthcare). Measurements were performed at least twice and the mean of values within $5 \%$ of each other recorded. Steady-state haemoglobin levels were measured during routine outpatient visits within 1 month of testing and were used to calculate 
$D \mathrm{~L}, \mathrm{CO}$ and $K \mathrm{CO}$ values corrected for haemoglobin level $(D \mathrm{~L}, \mathrm{CO}, \mathrm{c}$ and $K \mathrm{CO}, \mathrm{c})$ from $D \mathrm{~L}, \mathrm{CO}$ and $K \mathrm{CO}$, respectively. All lung function results were corrected to body temperature, pressure and saturated conditions. The lung function test results were expressed as a percentage of those predicted for height using the data of the European Community for Steel and Coal [13], corrected for ethnicity by reducing the lung volumes by $10 \%$. Adults were diagnosed as having a restrictive abnormality if their TLCpleth was $<80 \%$ of that predicted for standing height [14], an obstructive abnormality if their FEV1/FVC was $<81.4 \%$ in males and $<82.3 \%$ in females [14], and a mixed obstructive/restrictive lung function abnormality if both TLC and FEV1/FVC were reduced to these values. If, $20 \mathrm{~min}$ after administration of $200 \mu \mathrm{g}$ salbutamol, the FEV1 was at least $12 \%$ greater than the pre-bronchodilator measurement and had increased by $\geqslant 200 \mathrm{~mL}$ [14], the patients were diagnosed as having a positive response to bronchodilator therapy. Oxygen saturation was assessed by pulse oximetry (Ohmeda, Louisville, CO, USA). The measurement of oxygen saturation was made when the subject had rested and the saturation level reported was the stable level for $15 \mathrm{~min}$.

\section{ETCO measurements}

ETCO levels were measured using an ETCO monitor (CO$\mathrm{Stat}^{\mathrm{TM}}$; Natus Medical, San Carlos, CA, USA). A small sampling catheter was inserted $5 \mathrm{~mm}$ inside the nostril. Testing was completed within $3 \mathrm{~min}$ of quiet tidal breathing. After each measurement, the machine analysed the background $\mathrm{CO}$ level, which was then deducted from the measured value. The monitor also measured the background hydrogen concentration. If the hydrogen concentration exceeded $50 \mathrm{ppm}$, which interferes with the measurement of ETCO [15], the instrument

\begin{tabular}{lc}
\hline TABLE 1 & Lung function data \\
\hline FEV 1 & \\
FVC & $83(46-122)$ \\
FEV $\mathbf{1}$ /FVC & $82(45-109)$ \\
PEF & $0.85(0.75-0.96)$ \\
TLCpleth & $96(59-143)$ \\
FRCpleth & $83(53-113)$ \\
RVpleth & $97(68-146)$ \\
VCpleth & $88(29-170)$ \\
TL,Co & $83(47-103)$ \\
Kco & $56(21-85)$ \\
TL,CO,c & $80(47-118)$ \\
Kco,c & $75(32-105)$ \\
VA & $106(70-160)$ \\
\hline
\end{tabular}

Data are presented as the percentage of that predicted for standing height and expressed as median (range). FEV1: forced expiratory volume in one second; FVC: forced vital capacity; PEF: peak expiratory flow; TLCpleth: total lung capacity measured by plethysmography; FRCpleth: functional residual capacity measured by plethysmography; RVpleth: residual volume measured by plethysmography; VCpleth: vital capacity measured by plethysmography; $T L, \mathrm{CO}$ : transfer factor of the lung for carbon monoxide; $K \mathrm{CO}$ : transfer coefficient of the lung for carbon monoxide; $T L, C O, c$ : transfer factor of the lung for carbon monoxide corrected for haemoglobin levels; $K \mathrm{CO}_{\mathrm{C}} \mathrm{c}$ : transfer coefficient of the lung for carbon monoxide corrected for haemoglobin levels; VA: alveolar volume. terminated breath sampling and the ETCO test was aborted. Total bilirubin, absolute reticulocyte and haemoglobin levels were all recorded from routine blood samples taken during the patient's outpatient visit.

\section{Statistical analysis}

Differences were assessed for statistical significance using a Fisher's exact test. Correlations between HRCT findings, the degree of haemolysis and lung function results were assessed using Pearson's product moment correlation ( $\mathrm{r}$ ) or Spearman's rank correlation coefficient ( $\mathrm{rs}$ ), as appropriate. McNemar's Chi-squared test (confining analysis to subjects with divergent test results) was used to compare the sensitivity of HRCT and pulmonary function test results. Stepwise regression was used to identify key HRCT features linked to lung function abnormalities; all models satisfied the assumptions of multiple linear regression, as judged by testing for heteroscedasticity.

\section{RESULTS \\ Subjects}

Thirty-five SCD patients, homozygous for HbSS, were initially recruited to the study, but two failed to attend for pulmonary function testing or HRCT. Thus, 33 subjects (12 males and 21 females with a median (range) age of 36 yrs (17-67yrs), median (range) height of $167 \mathrm{~cm}(153-188 \mathrm{~cm})$ and median (range) weight of $69 \mathrm{~kg}(52-92 \mathrm{~kg})$ ) were examined. One patient had physician-diagnosed asthma and was taking regular antiasthma medication. Two of the patients were current smokers (median (range) 4.6 pack-yrs (0.4-8.8 pack-yrs)) and nine were ex-smokers (median (range) 1.9 pack-yrs (0.1-36.3 pack-yrs)).

\section{Pulmonary function test results}

There was a wide variation in the lung function of the cohort (table 1).

Eighteen patients had a restrictive, an obstructive or a mixed restrictive/obstructive abnormality. Nine patients had a restrictive lung function abnormality, five an obstructive abnormality and four a mixed restrictive/obstructive abnormality. Only one patient, who had a mixed restrictive/obstructive lung function abnormality, demonstrated a positive response to bronchodilator. This was not the known asthmatic patient.

\section{HRCT results}

Observer agreement for the scoring of HRCT patterns (expressed as the single-determination SD or the kappa coefficient, as appropriate) was within clinically acceptable limits [16] for all HRCT patterns except for the grading of peripheral vessel prominence (table 2).

A reticular pattern (fig. 1), lobar volume loss (fig. 2) and prominent central vessels (fig. 3 ) were the three most common abnormalities on HRCT. Traction bronchiectasis, interlobular septal thickening and nodules were uncommon patterns and hence excluded from further analysis.

HRCT abnormalities were evident in 30 patients, 12 with normal lung function. Lobar volume loss, prominent central vessels and/or a reticular pattern/ground-glass opacification were present in 30 cases and were more prevalent than reduction in FEV1 (14 out of 33; $\mathrm{p}<0.001)$, FVC (15 out of 33; $\mathrm{p}<0.001)$, TLC (13 out of 33 ; $\mathrm{p}<0.001)$ ), RV (10 out of 33; $\mathrm{p}<0.001)$, KCO (4 out of 33; p<0.001) and DL,CO (20 out of 
TABLE 2 High-resolution computed tomography (HRCT) data

\begin{tabular}{lccc} 
HRCT pattern & Prevalence & Median extent/severity & Observer variation \\
\hline Lobar volume loss & 67 & $2.0(0-8.0)$ & $0.61^{\#}$ \\
Central vessels & 70 & $8.0(0-19.0)$ & $0.55^{\#}$ \\
Peripheral vessels & 52 & $1.0(0-12.0)$ & $0.35^{\#}$ \\
Irregular linear opacities & 42 & $0.0(0-0.42)$ & $0.42^{\#}$ \\
Reticular pattern & 82 & $5.8(0-17.1)$ & $4.1^{*}$ \\
Ground-glass opacification & 58 & $0.83(0-57.5)$ & $4.36^{*}$ \\
Traction bronchiectasis & 9 & & \\
Interlobular septa & 18 & & \\
Nodules & 9 & & \\
\hline
\end{tabular}

Data are presented as \% or median (range), unless otherwise stated. " : weighted kappa coefficient; ": single determination SD (for "continuous" data).

33; $\mathrm{p}=0.03$ ). Lobar volume loss, prominent central vessels and a reticular pattern/ground-glass opacification were all present on HRCT in 12 of 18 subjects with a restrictive, obstructive or mixed ventilatory defect (table 3 ).
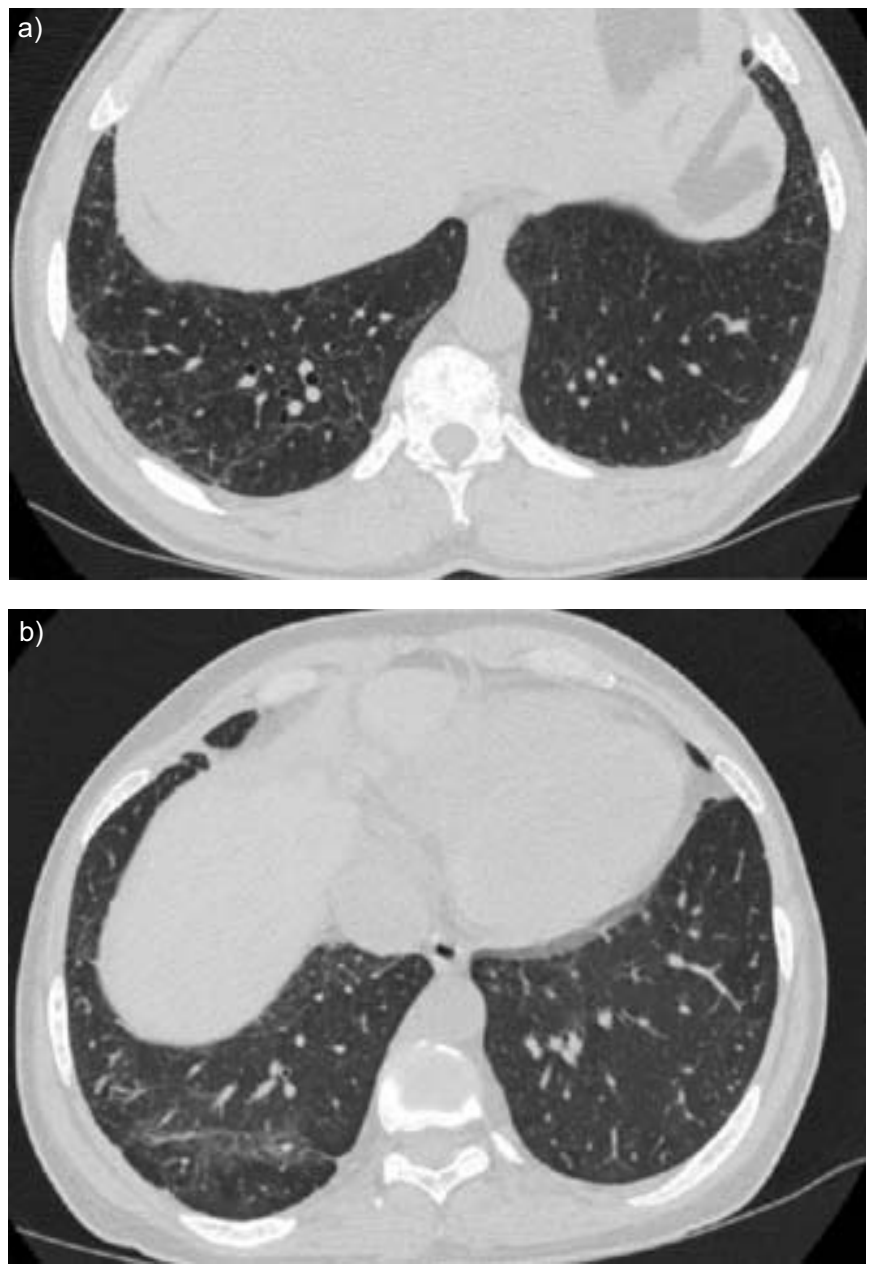

FIGURE 1. High-resolution computed tomography in two patients with sickle cell disease. a) Image through the lung bases demonstrating a fine reticular pattern without honeycombing. There is also some ground-glass opacification, but this pattern is of limited extent. b) Predominant ground-glass opacification is present at the lung bases; there is a subtle superimposed reticular pattern.
Ground-glass opacification and reticular abnormalities were strongly inter-related, both in presence and extent. Groundglass opacification was present in 19 out of 27 patients with a reticular pattern, but in none of the six patients without a reticular pattern $(p=0.003$, Fisher's exact test). The extents of a reticular pattern and ground-glass opacification were strongly correlated in the whole sample ( $r=0.77 ; \mathrm{p}<0.00005 ;$ fig. 4$)$ and in the 19 patients with ground-glass opacification $(r s=0.64$; $p=0.003$ ). Based on these observations, a total interstitial lung disease score, summing the extents of ground-glass opacification and a reticular pattern, was included in subsequent analyses.

The severity of lobar volume loss correlated with the extent of a reticular pattern $\left(\mathrm{rs}_{\mathrm{s}}=0.54 ; \mathrm{p}=0.001\right)$, ground-glass opacification $(\mathrm{r}=0.51 ; \mathrm{p}=0.002)$, total interstitial lung disease $\left(\mathrm{r}_{\mathrm{s}}=0.56\right.$; $\mathrm{p}<0.001)$ and irregular linear opacities ( $\mathrm{r} s=0.50 ; \mathrm{p}<0.001)$. Irregular linear opacities were correlated with the extent of a

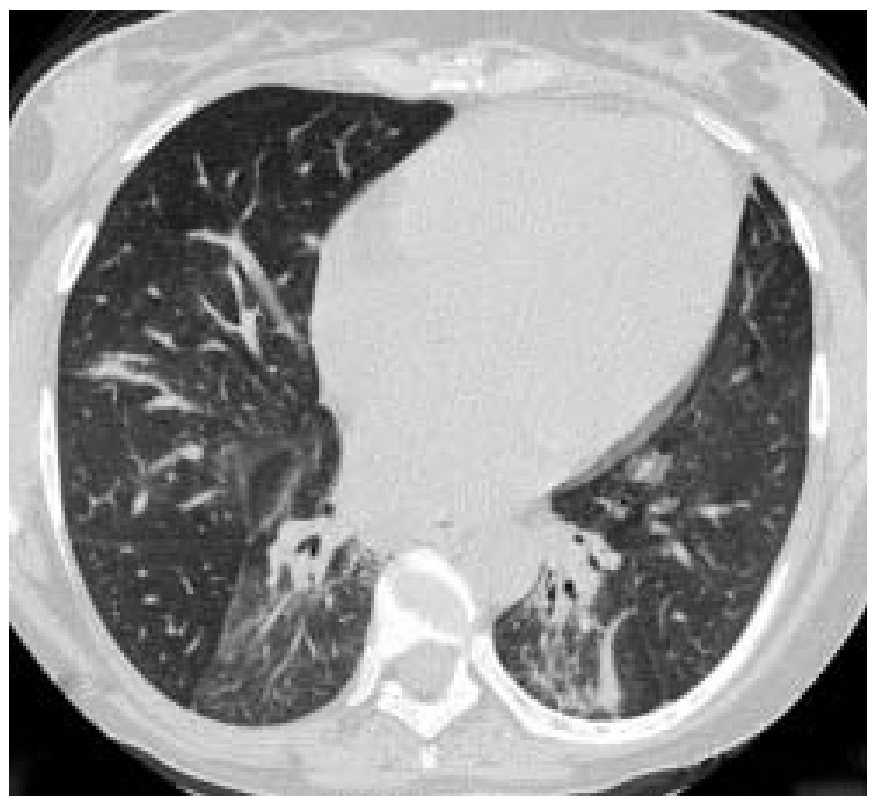

FIGURE 2. High-resolution computed tomography at the level of the pulmonary venous confluence showing marked volume loss in the lower zones; both oblique fissures are retracted posteriorly. 


\begin{tabular}{lccc} 
TABLE 3 & High-resolution computed tomography findings in patients with lung function abnormalities & Reticular pattern/ground glass \\
Subjects with lung function abnormalities $\mathbf{n}$ & Lobar volume loss & Prominent central vessels & \\
\hline Restrictive & & + & + \\
1 & + & + & + \\
2 & + & + & + \\
6 & + & + & + \\
Obstructive & + & - & + \\
1 & + & +
\end{tabular}

reticular pattern $\left(\mathrm{r}_{\mathrm{s}}=0.40 ; \mathrm{p}=0.02\right)$, ground-glass opacification $(\mathrm{r} s=0.46 ; \mathrm{p}<0.01)$ and total interstitial lung disease $\left(\mathrm{r}_{\mathrm{s}}=0.44\right.$; $\mathrm{p}<0.01)$.

\section{HRCT and lung function correlations}

On univariate analysis, lobar volume loss on HRCT was negatively related to the per cent predicted FEV1 ( $\mathrm{r}_{\mathrm{s}}=-0.44$; $\mathrm{p}<0.05)$, FVC ( $\mathrm{r} s=-0.46 ; \mathrm{p}<0.05)$ and TLC ( $\mathrm{rs}=-0.58 ; \mathrm{p}<0.0005)$. The extent of irregular linear opacities were negatively related to per cent predicted $\mathrm{DL}, \mathrm{CO}(\mathrm{rs}=-0.36 ; \mathrm{p}=0.04)$ and the severity of prominence of central vessels was negatively related to FVC $(\mathrm{rs}=-0.39 ; \mathrm{p}=0.02)$.

On stepwise regression, the results of all the lung function tests were linked to lobar volume loss on HRCT (table 4). After adjustment for lobar volume loss, the severity of central vessel prominence was negatively linked to FEV1 and FVC.

\section{Relationships between ETCO levels, other markers of haemolysis and lung function results}

Twenty-seven of the patients (including two current and seven ex-smokers) completed an assessment of ETCO levels. The

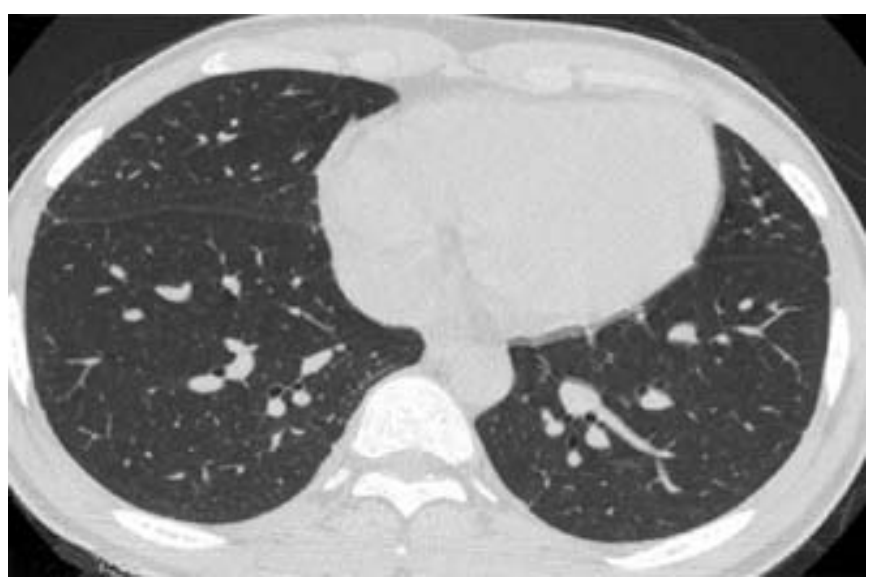

FIGURE 3. High-resolution computed tomography through the lower zones. The central pulmonary vessels in both lower lobes are prominent by comparison with the luminal diameter of the accompanying airway. remaining six patients had exhaled hydrogen levels $>50 \mathrm{ppm}$; their results, therefore, were excluded from the analysis. ETCO levels correlated positively with bilirubin levels ( $r_{s}=0.66$; $\mathrm{p}=0.0002)$ and the absolute reticulocyte count ( $\mathrm{r}_{\mathrm{s}}=0.70$; $\mathrm{p}=0.0002)$ and negatively with haemoglobin ( $\mathrm{r}_{\mathrm{s}}=-0.51$; $\mathrm{p}=0.008)$. ETCO levels correlated negatively with FEV1 ( $\mathrm{rs}=$ $-0.51 ; \mathrm{p}=0.006), \mathrm{VC}$ leth $(\mathrm{r}=-0.51 ; \mathrm{p}=0.006)$, specific airway conductance $(\mathrm{rs}=-0.39 ; \mathrm{p}=0.04)$ and arterial oxygen saturation measured by pulse oximetry $\left(r_{s}=-0.51 ; p=0.007\right)$.

\section{DISCUSSION}

It was demonstrated that the majority of the current patients with SCD had pulmonary abnormalities on HRCT examination and the HRCT findings correlated significantly with pulmonary function testing results. The most common HRCT abnormalities noted (reticular abnormalities, lobar volume loss and prominence of the central vessels) are likely to be chronic changes, as patients with a recent infection or vaso-occlusive

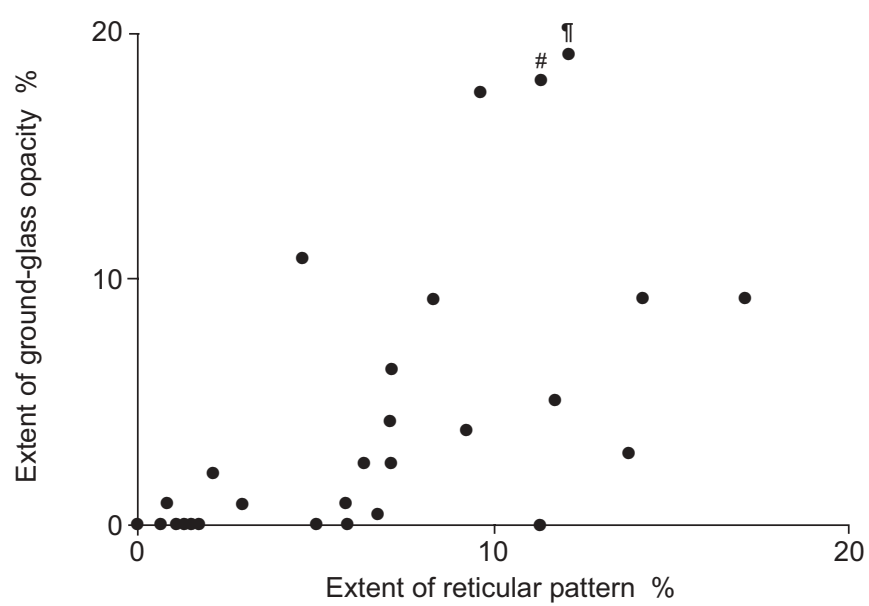

FIGURE 4. Relationship between two high-resolution computed tomography patterns. There was a close correlation between the extents of a reticular pattern and ground-glass opacification ( $r s=0.77 ; p<0.00005)$. Two patients ( ${ }^{*}$ and ") with a high extent of ground-glass opacity (27 and $58 \%$ ) are plotted at the extent of their reticular pattern (11 and $12 \%$, respectively). 


\begin{tabular}{|c|c|c|c|c|}
\hline TABLE 4 & $\begin{array}{l}\text { Relationships between pu } \\
\text { stepwise regression }\end{array}$ & n and high-resolution & tomography (HRC & lities on \\
\hline Lung function & $r^{2}$ value & HRCT & Coefficient $(95 \% \mathrm{Cl})$ & $\mathrm{p}$-value \\
\hline \multirow[t]{2}{*}{ FEV 1} & 0.32 & Lobar volume loss & $-3.6(-6.0--1.1)$ & 0.006 \\
\hline & & Prominent central vessels & $-1.0(-1.9--0.2)$ & 0.02 \\
\hline FVC & 0.43 & Lobar volume loss & $-3.3(-5.2--1.3)$ & 0.002 \\
\hline TLC & 0.21 & Lobar volume loss & $-2.5(-4.3--0.7)$ & 0.008 \\
\hline$V_{A}$ & 0.29 & Lobar volume loss & $-2.3(-3.6--1.0)$ & 0.001 \\
\hline DL,CO & 0.16 & Lobar volume loss & $-2.5(-4.6--0.4)$ & 0.03 \\
\hline
\end{tabular}

crisis were excluded from this study. The HRCT findings suggest that fibrotic interstitial abnormalities are common in adults with SCD, as the majority of the patients had reticular abnormalities and/or lobar volume loss. Reticular abnormalities on HRCT consistently represent interstitial fibrosis in other pulmonary diseases [17] and lobar volume loss is frequently present in fibrotic lung disease. Ground-glass opacification is less specific [18], it sometimes denotes fine fibrosis [19-21], but can also be indicative of reversible disease, including inflammation, low-grade infection, and alveolar haemorrhage. However, the inter-relationships that were demonstrated between the HRCT scores for reticular abnormalities, ground-glass opacification, irregular linear opacities and loss of lobar volume suggest that these patterns have a linked pathogenesis.

Quantification of CT patterns and the relationship of the results to lung function abnormalities have been determined in a number of diffuse lung diseases, including idiopathic pulmonary fibrosis [22] and lung fibrosis associated with systemic fibrosis [23, 24], sarcoidosis [25] and small airways disease $[26,27]$. The method of scoring of the reticular patterns, ground-glass opacification and nodules used in the current study has been previously shown to give good observer agreement [28]. The semi-quantitative measurement of volume loss and vessel prominence used in the current study has not been widely tested. However, the results for lobar volume loss and central vessel prominence were believed to be robust as there was good observer agreement. This was not true for the results of peripheral vessel scoring. Hence, those results were excluded from further analysis.

The abnormalities demonstrated on HRCT correlated appropriately with lung function abnormalities. For example, increasing lobar volume loss on HRCT was linked to decreasing FVC levels in the whole cohort and, in the patients with restrictive abnormalities, volume loss on HRCT was almost invariable. These correlations suggest that the HRCT findings are important. An independent relationship between reductions in FEV1 and FVC and central vessel prominence was also found; in addition, prominent central vessels were found on the HRCT examinations of eight out of the nine patients with restrictive abnormalities. Pulmonary hypertension is common in SCD patients with SCLD and such patients have restrictive lung function abnormalities [1]. It is, therefore, tempting to speculate that the central vessel prominence noted in association with reduced FEV1 and FVC and restrictive lung function abnormalities reflects changes related to pulmonary hypertension. This hypothesis merits testing.

ETCO levels also correlated with the pulmonary function results. A number of factors influence ETCO levels, but it was felt that these were appropriately considered. For example, ETCO levels are raised during the acute symptomatic phase of a URTI [29]; hence, measurements were not taken from patients within 2 weeks of a URTI. Room air was analysed as an index of inhaled $\mathrm{CO}$, so that the rate of endogenously produced $\mathrm{CO}$ could be appropriately assessed [30]. Since there is a relatively long-lasting effect of $\mathrm{CO}$ exposure, as carboxyhaemoglobin has a half life of up to $6 \mathrm{~h}$, it is also necessary to take into account prior exposure to high levels of $\mathrm{CO}$ from gas heaters, internal combustion engines and tobacco smoke. Only two of the patients, however, were smokers and both stated they had not smoked for the $24 \mathrm{~h}$ prior to testing, as requested. The present authors demonstrated that ETCO levels reflected the degree of haemolysis in SCD adults, as assessed by the total bilirubin and haemoglobin levels and the reticulocyte count. Thus, the demonstration of a significant relationship between pulmonary function and ETCO levels is not surprising, as a correlation between haemolysis and pulmonary function in SCD would be expected. Plasma haemoglobin is a rapid and effective scavenger of nitric oxide (NO), as well as catalysing the formation of reactive oxygen and nitrogen species [31]. Reduced NO bioavailability enhances adhesion, as NO under normal physiological conditions inhibits the production of adhesive molecules such as vascular cell adhesion molecule-1 and E-selectin. Hence, the adhesion of the erythrocytes to the vascular endothelium is increased and leads to direct endothelium injury. The finding that ETCO levels negatively correlate with lung function results in SCD patients suggest that this noninvasive assessment of haemolysis might be useful to identify SCD patients with lung function abnormalities.

In conclusion, the current results suggest that high-resolution computed tomography examination and/or noninvasive assessment of haemolysis might facilitate identification of sickle cell disease patients with respiratory function impairment. These tests may be particularly useful in those patients 
unable to complete pulmonary function tests. More of the patients had abnormalities on high-resolution computed tomography than on lung function testing, which suggests that high-resolution computed tomography is a more sensitive detector of respiratory abnormalities than lung function testing. This hypothesis merits testing by serially assessing sickle cell disease patients to determine whether those with only high-resolution computed tomography abnormalities subsequently develop lung function abnormalities.

\section{REFERENCES}

1 Powars D, Weidman JA, Odom-Maryon T, Niland JC, Johnson C. Sickle cell chronic lung disease: prior morbidity and the risk of pulmonary failure. Medicine (Baltimore) 1988; 67: 66-76.

2 Hansell DM. High-resolution computed tomography in the evaluation of fibrosing alveolitis. Clin Chest Med 1999; 20: 739-760.

3 Hansell DM. Computed tomography of diffuse lung disease: functional correlates. Eur Radiol 2001; 11: 1666-1680.

4 Hansell DM, Armstrong P, Lynch DA, McAdams HP. Basic HRCT patterns of lung disease. In: Hansell DM, Armstong P, Lynch DA, McAdams, eds. Imaging of Diseases of the Chest. Philadelphia, Elsevier Mosby, 2005; pp. 69-181.

5 Aquino SL, Gamsu G, Fahy JF, et al. Chronic pulmonary disorders in sickle cell disease: findings at thin-section CT. Radiology 1994; 193: 807-811.

6 Engel RR, Rodkey FL, Krill CE Jr. Carboxyhemoglobin levels as an index of hemolysis. Pediatrics 1971; 47: 723-730.

7 Tenhunen R, Marver HS, Schmid R. Microsomal heme oxygenase. Characterization of the enzyme. J Biol Chem 1969; 244: 6388-6394.

8 Berk PD, Rodkey FL, Blaschke TF, Collison HA, WaggonerJG. Comparison of plasma bilirubin turnover and carbon monoxide production in man. J Lab Clin Med 1974; 83: 29-37.

9 Solanki DL, McCurdy PR, Cuttitta FF, Schechter GP. Hemolysis in sickle cell disease as measured by endogenous carbon monoxide production. A preliminary report. Am J Clin Pathol 1988; 89: 221-225.

10 Coburn RF, Williams WJ, Kahn SB. Endogenous carbon monoxide production in patients with hemolytic anemia. $J$ Clin Invest 1966; 45: 460-468.

11 Sylvester KP, Patey RA, Rafferty GF, Rees D, Thein SL, Greenough A. Exhaled carbon monoxide levels in children with sickle cell disease. Eur J Pediatr 2005; 164: 162-165.

12 Austin JH, Muller NL, Friedman PJ, et al. Glossary of terms for CT of the lungs: recommendations of the Nomenclature Committee of the Fleischner Society. Radiology 1996; 200: 327-331.

13 Quanjer PH, Tammeling GJ, Cotes JE, Pedersen OF, Peslin R, Yernault JC. Lung volumes and forced ventilatory flows. Report Working Party Standardization of Lung Function Tests, European Community for Steel and Coal Official Statement of the European Respiratory Society. Eur Respir J 1993; 6: Suppl. 16, 5-40.

14 American Thoracic Society, Lung function testing: selection of reference values and interpretative strategies. Am Rev Respir Dis 1991; 1444: 1202-1218.
15 Vreman HJ, Mahoney JJ, Stevenson DK. Electrochemical measurement of carbon monoxide in breath: interference by hydrogen. Atmospheric Environment. Part A. General Topics 1993; 27: 2193-2198.

16 Chinn S. Statistics in respiratory medicine. 2. Repeatability and method comparison. Thorax 1991; 46: 454-456.

17 Muller NL, Miller RR, Webb WR, Evans KG, Ostrow DN. Fibrosing alveolitis: CT-pathologic correlation. Radiology 1986; 160: 585-588.

18 Collins J, Stern EJ. Ground-glass opacity at CT: the ABCs. AJR Am J Roentgenol 1997; 169: 355-367.

19 Remy-Jardin M, Giraud F, Remy J, Copin MC, Gosselin B, Duhamel A. Importance of ground-glass attenuation in chronic diffuse infiltrative lung disease: pathologic-CT correlation. Radiology 1993; 189: 693-698.

20 Remy-Jardin M, Remy J, Giraud F, Wattinne L, Gosselin B. Computed tomography assessment of ground-glass opacity: semiology and significance. J Thorac Imaging 1993; 8: 249-264.

21 Leung AN, Miller RR, Muller NL. Parenchymal opacification in chronic infiltrative lung diseases: CT-pathologic correlation. Radiology 1993; 188: 209-214.

22 Wells AU, King AD, Rubens MB, Cramer D, du Bois RM, Hansell DM. Lone cryptogenic fibrosing alveolitis: a function-morphologic correlation based on the extent of disease of thin-section computed tomography. Am J Respir Crit Care Med 1997; 155: 1367-1375.

23 Wells AU, Hansell DM, Rubens MB, Cailes JB, Black CM, $\mathrm{du}$ Bois RM. Functional impairment in lone cryptogenic fibrosing alveolitis and fibrosing alveolitis associated with systemic sclerosis: a comparison. Am J Respir Crit Care Med 1997; 155: 1657-1664.

24 Wells AU, Cullinan P, Hansell DM, et al. Fibrosing alveolitis associated with systemic sclerosis has a better prognosis than lone cryptogenic fibrosing alveolitis. Am J Respir Crit Care Med 1994; 149: 1583-1590.

25 Hansell DM, Milne DG, Wilsher ML, Wells AU. Pulmonary sarcoidosis: morphologic associations of airflow obstruction at thin-section CT. Radiology 1998; 209: 697-704.

26 Hansell DM, Rubens MB, Padley SPG, Wells AU. Obliterative bronchiolitis: individual CT signs of small airways disease and functional correlation. Radiology 1997; 203: 721-726.

27 Roberts HR, Wells AU, Milne DG, et al. Airflow obstruction in bronchiectasis: correlation between computed tomography features and pulmonary function tests. Thorax 2000; 55: 198-204.

28 Collins CD, Wells AU, Hansell DM, et al. Observer variation in pattern type and extent of disease in fibrosing alveolitis on thin section computed tomography and chest radiography. Clin Radiol 1994; 49: 236-240.

29 Vreman HJ, Wong RJ, Stevenson DK. Exhaled carbon monoxide in asthma. J Pediatr 2000; 137: 889-891.

30 Vreman HJ, Wong RJ, Harmatz P, Fanaroff AA, Berman B, Stevenson DK. Validation of the Natus CO-Stat End Tidal Breath Analyzer in children and adults. J Clin Monit Comput 1999; 15: 421-427.

31 Reiter CD, Wang X, Tanus-Santos JE, et al. Cell-free hemoglobin limits nitric oxide bioavailability in sickle-cell disease. Nat Med 2002; 8: 1383-1389. 